\title{
Nikolai G. Tchernichévski: contribuição à filosofia da história na Rússia do século XIX*
}

\author{
Nikolay G. Chernyshevsky: contribution to the philosophy of history in \\ 19th-century Russia
}

\author{
Camilo José Teixeira Lima Domingues \\ camilodomingues@hotmail.com \\ Mestrando \\ Universidade Federal Fluminense \\ Rua Tenente Azevedo, 256 - Casa 12 - Aclimação \\ 01528-020 - São Paulo - SP \\ Brasil
}

\section{Resumo}

Este artigo tem como objetivo analisar e sistematizar as contribuições do escritor e jornalista revolucionário russo Nikolai Gavrílovitch Tchernichévski (1828-1889) à filosofia da história. Para tanto, partir-se-á de três obras filosóficas do autor tomadas como referência: "O princípio antropológico na filosofia", "O caráter do conhecimento humano" e "As relações estéticas da arte com a realidade". A partir da primeira obra, será analisado o debate acerca dos postulados das assim chamadas ciências exatas e ciências morais, vigente à época (1860) e motivo de controvérsias e discussões filosóficas até os dias de hoje. Em "O caráter do conhecimento humano" serão analisados e discutidos o papel que o autor confere à história e a sua concepção de desenvolvimento histórico. $\mathrm{O}$ terceiro ensaio do autor servirá à discussão da história como representação. Ao final, evidencia-se a marcante influência da filosofia feuerbachiana na obra de Tchernichévski e é elaborado o esboço de uma possível filosofia da história tchernichevskiana.

\section{Palavras-chave:}

Filosofia da história; Materialismo histórico; Historiografia do século XIX.

\begin{abstract}
This article aims to systematize and analyze the contributions of the Russian revolutionary writer and journalist Nikolai Gavrilovich Chernyshevsky (1828-1889) to the philosophy of history. For this purpose, three philosophical works of the author will serve as references: "The anthropological principle in philosophy", "The character of human knowledge" and "The aesthetic relations between art and reality". The first of these works leads to an analysis of the discussion on the tenets of the so-called exact sciences and moral sciences, which were current at the time (1860) and are still the subject of philosophical controversies to the present day. On its turn, "The character of human knowledge" brings the discussion on the role attributed by the author to history and on his conception of historical development. And his third essay under analysis leads to the discussion on history as representation. At the end, the remarkable influence of Feuerbach's philosophy on his work is highlighted, and a sketch of a possible Chernyshevskyan philosophy of history is presented.
\end{abstract}

\section{Keywords}

Philosophy of history; Historical materialism; $19^{\text {th }}$ century historiography.

Enviado em: 8/10/2013

Aprovado em: 26/12/2013

\footnotetext{
* Este artigo insere-se no projeto de pesquisa "Nikolai Gavrílovitch Tchernichévski e a intelligentsia russa: filosofia, arte e revolução na segunda metade do século XIX", desenvolvido no PPGH-UFF (nível de mestrado) e orientado pelo Prof. Dr. Daniel Aarão Reis Filho, a quem agradeço a imensa disponibilidade e a atenciosa parceria. Agradeço também ao Prof. Dr. Mário Grynspan, pelo incentivo a partir do qual surgiu este artigo, ao colega Roger Anibal Lambert Silva pela leitura atenta e por seus comentários e a Yuri Martins de Oliveira por sua ajuda na transliteração russo-português. Por último, agradeço aos pareceristas, editores e revisores desta revista pelos comentários e pelas sugestões e correções pertinentes. Este artigo contou com financiamento da CAPES.
} 
Este artigo pretende compilar, com base nos três ensaios filosóficos mais relevantes de Nikolai G. Tchernichévski, as concepções de história desse autor de forma sistemática, para o delineamento de uma possível filosofia da história tchernichevskiana. Em "O princípio antropológico na filosofia" será analisado o debate acerca dos postulados das assim chamadas ciências exatas e ciências morais, vigente à época (1860) e motivo de controvérsias e discussões filosóficas até os dias de hoje. Em "O caráter do conhecimento humano" serão discutidos o papel que o autor confere à história e a sua concepção de desenvolvimento histórico. A sua tese "As relações estéticas da arte com a realidade" servirá à discussão da história como representação. ${ }^{1}$

O principal objetivo deste trabalho é trazer à luz as ideias e os trabalhos de um dos mais influentes pensadores russos de meados do século XIX. Tchernichévski pertenceu à geração russa dos anos 1860, responsável pela assimilação, contextualização e divulgação do debate contemporâneo europeu em torno da filosofia alemã (hegelianos e novos hegelianos) e das ideias socialistas francesas, bem como do liberalismo econômico clássico inglês. Sua obra literária e filosófica influenciaria toda a intelectualidade e juventude revolucionárias russas na segunda metade do século XIX.

Durante seus estudos de literatura, na Universidade de São Petersburgo, Tchernichévski conheceu os trabalhos dos principais expoentes da filosofia alemã do século XIX, Georg Wilhelm Friedrich Hegel (1770-1831) e Ludwig Andreas Feuerbach (1804-1872). A partir de então, acumulou intensa crítica contra o

108 idealismo filosófico, crítica que o acompanharia durante toda a sua vida, fosse em seus ensaios filosóficos, fosse em seus trabalhos políticos ou estéticos. No campo do pensamento histórico, Tchernichévski foi adepto do humanismo ou da filosofia antropológica feuerbachiana e travou um verdadeiro embate com a escola filosófica tradicional, à qual qualificava ironicamente de ilusionista.

É importante salientar que qualquer tentativa de sistematização teórica de um pensador russo membro da intelligentsia reformista ou revolucionária em meados do século XIX não pode deixar de considerar um aspecto: havia nos trabalhos daqueles pensadores a convicção de que as suas palavras tinham força material, de que não jaziam apenas nos papéis. O calor do tempo aproximava, mais que o comum, a filosofia e a política. Tchernichévski trouxe contribuições importantes para ambas, apesar de algumas limitações que são compreensíveis dada a conjuntura repressiva e limitante em que desenvolveu os seus trabalhos.

\section{As ciências exatas e as ciências morais}

No seu ensaio "O Princípio Antropológico na Filosofia"(1860), Tchernichévski comenta o trabalho de P. L. Lavrov² "Ensaio sobre os Problemas da Filosofia

\footnotetext{
${ }^{1}$ A análise proposta neste artigo será feita tendo como base as traduções dos referidos textos de Tchernichévski para o inglês publicadas em 1953 sob o título de Selected Philosophical Essays. Essa compilação foi editada pela extinta Moscow Foreign Languages Publishing House, editora estatal da ex-URSS responsável pela publicação de obras russas em línguas estrangeiras. Acreditamos que a utilização dessas traduções não acarretará prejuízo na interpretação das obras.

2 Piótr Lávrovitch Lavrov (1823-1900), teórico e filósofo russo. Propagandista de ideias revolucionárias durante os anos 1860 .
} 
Prática", publicado no mesmo ano. Faz desse trabalho a sua tentativa mais bem sistematizada de incorporar o pensamento feuerbachiano à sua filosofia materialista. O ensaio é dividido em duas partes. Na primeira delas, Tchernichévski tece considerações críticas ao ensaio de Lavrov - apesar de salientar a importância do autor como primeiro porta-voz russo do antropologismo filosófico - e aponta as contribuições e limitações dos autores citados por Lavrov em seu trabalho: Jules Simon, ${ }^{3}$ John Stuart Mill e Pierre-Joseph Proudhon. O fiel de sua balança crítica é o nível de correspondência dos trabalhos desses pensadores em relação ao assim chamado pensamento progressista contemporâneo, a saber, a filosofia materialista humanista de Ludwig Feuerbach, que, segundo ele, superaria até mesmo os trabalhos dos demais hegelianos de esquerda. Ainda the serve como critério de avaliação e legitimação da atividade desses pensadores a relevância social e política do tema abordado e a coerência entre teoria e prática, aspecto em que critica duramente Jules Simon e Mill.

À medida que dialoga com os autores elencados acima na primeira parte de seu ensaio, Tchernichévski começa a esboçar os primeiros traços do que seriam os seus princípios antropológicos na filosofia - sempre de acordo com o materialismo humanista feuerbachiano - e que serão mais bem desenvolvidos na segunda parte. Colocando inúmeros exemplos, com um claro objetivo didático e de popularização daquela que, segundo ele, seria a filosofia progressista e redentora, e seguindo estritamente os limites permitidos de sua escrita esópica, a fim de driblar a censura czarista, Tchernichévski elabora uma obra que, apesar de questionável em sua profundidade e assertividade filosófica, servirá como material de propaganda - e mesmo de agitação - para a preparação política dos jovens radicais russos da geração de 1860 .

Nessa apresentação e defesa de suas concepções filosóficas materialistas, Tchernichévski não poderia passar ao largo da discussão da cientificidade das ciências morais, posto que na batalha por sua legitimação em meio às demais ciências exatas, estava em disputa algo mais que uma simples querela epistemológica. Em seu trabalho, ele reivindicava para as ciências morais a sua validade como verdade científica concreta e contestava a concepção segundo a qual estas seriam meras opiniões ou memórias desconectadas de uma lógica ou lei demonstrável, incapazes de postular os seus próprios axiomas e de traçar os caminhos necessários ao pensamento e desenvolvimento humanos. Demarcar o caráter científico das ditas ciências morais não Ihe interessava apenas como uma contribuição à filosofia, mas - e, talvez, principalmente - como uma necessária racionalização da ação política - de acordo com os preceitos do materialismo filosófico e do então promissor socialismo francês -, como instrumento de crítica capaz de questionar e enfrentar as instituições políticas tradicionais.

Em suas considerações a respeito do caráter científico atribuível ou não às ciências morais em meados do século XIX, Tchernichévski traça a linha que então as separava das ciências exatas: 


\begin{abstract}
A palavra "ciência" em inglês de forma alguma cobre todos os ramos do conhecimento que este termo abrange entre nós e entre as outras nações continentais. Por ciência, os ingleses entendem: matemática, astronomia, física, química, botânica, zoologia, geografia - aqueles ramos do conhecimento que chamamos de ciências exatas e aqueles intimamente ligados a eles. Mas eles não aplicam este termo à história, psicologia, filosofia moral, ou à metafísica (TCHERNICHÉVSKI 1953b, p. 88 , tradução nossa). ${ }^{4}$
\end{abstract}

Segundo o autor, até então, havia uma diferença básica que justificava tal linha demarcatória. As ciências exatas proporcionariam resultados unívocos, aceitáveis amplamente tanto pela comunidade científica quanto pela sociedade em geral e, no limite, inquestionáveis, enquanto as ciências morais poderiam proporcionar apenas uma plêiade de opiniões diversas, em torno das quais não se poderiam articular os resultados das investigações dos diversos cientistas.

Sendo o caráter de cientificidade de qualquer área do conhecimento definido pela univocidade e aceitabilidade universal de seus resultados e pela presumibilidade destes a partir de leis deduzidas e exaustivamente comprovadas, as ciências morais estariam, por seu próprio objeto e pelas próprias características de seus resultados - mais argumentativos que científicos - alijadas do paradigma científico. Cabe lembrar que tal questão não foi submetida apenas a Tchernichévski ou a pensadores materialistas do século XIX que porventura pudessem concebê-las por interesses tanto filosóficos como políticos. A grande discussão sobre o caráter científico das ciências morais surge pari passu ao avanço das assim chamadas ciências exatas a partir das descobertas científicas e do advento e predomínio do empirismo em virtude da expansão do ensino científico e universitário desde o início do século XVI na Europa Ocidental. O avanço irresistível das ciências exatas abalou o lugar de destaque até então improfanável das ciências do pensamento.

A filosofia de Hegel foi determinante para o debate a respeito do caráter da história e das demais ciências morais em "O Princípio Antropológico na Filosofia". A partir dos ensinamentos sobre a obra hegeliana obtidos pela mão de divulgadores russos e pelo estudo das obras dos hegelianos de esquerda, Tchernichévski vaticinará o fim da dicotomia entre as ciências exatas e as ciências morais em relação à sua cientificidade. Para o autor, a consolidação científica das ciências morais ocorria no instante mesmo da elaboração de sua obra e não se devia à descoberta e elaboração de novos e específicos métodos de investigação e de validação de resultados por parte dessas ciências, mas, antes, pela assimilação dos métodos e princípios científicos próprios das ciências exatas. A aquisição do postulado científico custaria às ciências morais a sua subsunção aos métodos próprios das ciências naturais: "Todos os pensadores progressistas entre aqueles que estão estudando as ciências morais começaram

\footnotetext{
${ }^{4}$ No original: "The word 'science' in English does not by any means cover all the branches of knowledge that this term covers among us, and among the other continental nations. By science the English mean: mathematics, astronomy, physics, chemistry, botany, zoology, geography - those branches of knowledge that we call the 'exact' sciences, and those closely related to them in character. But they do not apply this term to history, psychology, moral philosophy, or to metaphysics".
} 
a tratar tais questões com a ajuda de métodos precisos similares àqueles pelos quais os problemas das ciências naturais são tratados" (TCHERNICHÉVSKI 1953b, p. 92, tradução nossa). ${ }^{5}$

Ao tomar de empréstimo das ciências exatas (ou ciências naturais) os seus métodos próprios e consagrados de investigação, as ciências morais adquiririam necessariamente, e de partida, dois princípios básicos daquelas, segundo Tchernichévski: o monismo (ou não dualismo) e o princípio da causalidade.

A geração de intelectuais e pensadores à qual pertenceu Tchernichévski vivenciou um avanço - e uma crença - sem paralelo em uma ciência natural particular, a química. Descobria-se que compostos químicos (átomos e moléculas) semelhantes estavam presentes nos mais diversos seres, fossem animados ou inanimados. Os novos adventos científicos - acabara de ser editada $A$ origem das espécies, de Charles Darwin - foram acolhidos como verdadeira graça no seio do pensamento materialista: o ser era uno. Extinguia-se, portanto, ao menos cientificamente e filosoficamente, o dualismo religioso - a separação entre ser e espírito. Em uma aritmética rápida, os materialistas, que passaram à história como mecanicistas ou deterministas - entre os quais, para grande parte de crítica ocidental, insere-se com destaque Tchernichévski -, empenharam-se em tratar os fenômenos químicos e morais da vida a partir dos mesmos pressupostos e esquemas metodológicos.

Se um dos alicerces das ciências exatas é o princípio da causalidade, que garante a comprovação e a presumibilidade dos fatos, que, por sua vez, são o que conferem o título de ciência a essa ou aquela área do conhecimento; se os fenômenos da moral são apenas manifestações particulares de uma engrenagem físico-química universal e, dessa forma, em sua origem, remontam ao campo das ciências exatas; então, também se aplica às ciências morais o princípio da causalidade.

É definitivamente sabido, por exemplo, que todos os fenômenos no mundo moral originam-se um dos outros e de circunstâncias externas em conformidade com a lei de causalidade, e, nesta base, todas as hipóteses de que pode haver algum fenômeno que não surja de um fenômeno precedente ou de uma circunstância externa são consideradas falsas (TCHERNICHÉVSKI 1953b, p. 94, tradução nossa). ${ }^{6}$

Em "O princípio antropológico na filosofia", Tchernichévski enumera diversos exemplos de aplicabilidade de seus postulados epistemológicos em diversas áreas das ciências morais, como a psicologia e a filosofia. Dedica-se, em especial, em apresentar e explicar o método de dedução negativa - dentre todos os tomados de empréstimo das ciências exatas, aquele que mais serviço teria a prestar às ciências morais. As dificuldades inerentes dessas últimas em afirmar fatos e provas,

\footnotetext{
${ }^{5}$ No original: "All the progressive thinkers among those who are studying the moral sciences have begun to work out these problems with the aid of precise methods similar to those by which the problems of the natural sciences are being worked out".

6 No original: "It is definitely known, for example, that all the phenomena of the moral world originate from one another and from external circumstance in conformity with the law of causality, and on this basis all assumptions that there can be any phenomena that do not arise from preceding phenomena and from external circumstances are regarded as false".
} 
em reconstituí-los e em auferir resultados seriam satisfatoriamente contornadas pela maior facilidade em negá-los. Como Tchernichévski ironiza em sua obra, não seria necessário descer ao centro da Terra para se confirmar que não há inferno. As demais verdades científicas disponíveis ao cientista o tornariam capaz de presumir a inexistência do inferno com alto grau de confiabilidade. Assim se poderia proceder também no tratamento científico dos problemas morais.

Dessa forma, diante do problema epistemológico posto às ciências morais em relação ao seu caráter científico, Tchernichévski não vai em busca das particularidades e especificidades dessas últimas na tentativa de fundar uma nova epistemologia, paralela e tão válida quanto a das ciências exatas, porém com os seus procedimentos próprios. Em Tchernichévski, as ciências morais assumem os postulados e procedimentos das ciências exatas. As questões morais insolúveis dentro desse esquema estariam, segundo o autor, apenas no aguardo de novas descobertas e do promissor passar do tempo para serem solucionadas. A resolubilidade das questões científicas seria apenas uma variável - necessária - do tempo: "o homem não escapará da verdade, pois no presente estado das relações humanas ela está, ano após ano, se tornando uma necessidade maior e mais imperativa" (TCHERNICHÉVSKI 1953b, p. 135, tradução nossa). ${ }^{7}$

Em meados do século XIX, fosse na Europa Ocidental ou na Rússia, a profusão de pensadores materialistas das mais diversas correntes - monistas, empiriomonistas, machistas, ${ }^{8}$ deterministas, mecanicistas - não permitiu que Tchernichévski pecasse por originalidade. Como já foi salientado, foi a partir de

112 sua interpretação da obra de Ludwig Feuerbach que o autor elaborou o ensaio em questão, na tentativa de apresentá-lo ao público russo e de propor o verdadeiro princípio antropológico na filosofia, a "antropologia da revolução" (GARCIA-VALVERDE; INGERFLOM 2009, p. 164) ou o "materialismo revolucionário" (RANDALL 1967, p. 74). Para além, no entanto, do componente ideológico do pensador em questão está o próprio problema epistemológico posto às ciências morais. Desde antes da tentativa de solução realizada por Tchernichévski e mesmo após esta e a de tantos outros, motivados pelos mais diversos e insondáveis desígnios, tal problema está posto e ainda continua colocado à ciência nos dias de hoje, sendo tema de muitos trabalhos e discussões.

O que nos interessa, por ora, é o caráter atribuído por Tchernichévski às ciências morais: estas desenvolvem seus trabalhos, exercem seus métodos e emitem seus resultados tais quais as ciências exatas. Também elas são tributárias dos princípios do monismo e da causalidade. As suas questões ainda insolúveis não se deviam a um suposto caráter peculiar às ciências morais, mas apenas ao estágio ainda incipiente de seu desenvolvimento. Os seus fatos, provas e resultados são tão irrefutáveis quanto aqueles comprovados pelas ciências exatas. Veremos, a seguir, como as considerações de Tchernichévski em torno da filosofia da ciência repercutirão no tema central deste artigo, a sua possível filosofia da história.

\footnotetext{
7 No original: "man will not escape truth, because in the present state of human affairs it is, year after year, becoming an ever greater and more imperative necessity".

${ }^{8}$ O termo refere-se aos adeptos de Ernst Mach (1838-1916), físico e filósofo positivista austríaco.
} 


\section{História e ciência}

No seu ensaio "O caráter do conhecimento humano" (1885), Tchernichévski polemiza com as concepções filosóficas idealistas e materialistas, fazendo a defesa das últimas. Ironicamente, o autor qualifica a filosofia idealista (o neokantismo e o subjetivismo idealista) de ilusionismo e denuncia a influência que ela estaria exercendo à época sobre os naturalistas. Tchernichévski acredita que os próprios naturalistas, por seu empirismo e superficialidade teórico-filosófica, corriam o risco de serem contaminados por uma teoria subjetivista e, no limite, irracional e ilógica. Põe em questão o próprio caráter do conhecimento humano em termos de se ele seria acessível em sua essência ou apenas percebido distorcidamente pelos falíveis sentidos humanos.

Para Tchernichévski, a limitação e a falibilidade da cognição humana não interferem na essência concreta, material e prática do conhecimento. As novas e constantes descobertas científicas não anulariam a concretude do conhecimento já consagrado, nem seriam capazes de negá-lo em sua essência. Apenas agregariam novo conhecimento. Tal dinâmica, determinada pela própria natureza humana, conferiria um caráter relativo ao conhecimento humano, sem, no entanto, negar a sua validade ou a sua aproximação da verdade.

O nosso conhecimento é conhecimento humano. As faculdades cognitivas do homem são limitadas, assim como todas as suas faculdades. Nesse sentido, o caráter do nosso conhecimento é determinado pelo caráter de nossas forças cognitivas. [...] Em geral, a ampliação do nosso conhecimento é acompanhada por uma mudança em alguma parte do nosso estoque anterior de conhecimento. [...] Veremos que o caráter essencial do conhecimento factual permaneçe inalterado, não importa o quanto ele tenha se ampliado (TCHERNICHÉVSKI 1953c, p. 179, tradução nossa). ${ }^{9}$

Para os ilusionistas, no entanto, a relatividade do conhecimento humano denotaria a sua invalidade e incapacidade de aferir o objeto, a realidade, em sua essência. Com seu ensaio, Tchernichévski se contrapõe a essa concepção, sem abrir mão de extensa exemplificação e também de seu tom irônico característico.

Após citar, como exemplos, o desenvolvimento científico do conhecimento sobre a água, a aritmética e mesmo sobre atividades triviais (como a escrita de uma carta), Tchernichévski empreende a análise do conhecimento histórico, considerando a história uma ciência cuja "dose de inautenticidade é maior" e mostrando como até mesmo um conhecimento tão frágil tem uma essência que não pode ser negada.

Tome-se, por exemplo, uma das ciências na qual a dose de inautenticidade é maior, a saber, a história. "Os atenienses derrotaram os Persas em Maratona" é autêntico ou duvidoso? [...] Os detalhes de nossa informação sobre, digamos, a batalha de Maratona, podem e devem ser verificados e muitos deles que parecem ser bastante autênticos podem provar ser

\footnotetext{
${ }^{9}$ No original: "Our knowledge is human knowledge. Man's cognitive powers are limited, as are all his powers. In this sense of the term, the character of our knowledge is determined by the character of our cognitive powers. [...] In general, the widening of knowledge is accompanied by a change in some of our former stock of knowledge. [...] We will see that the essential character of factual knowledge remains unchanged, no matter how much it may have widened".
} 
duvidosos e inverídicos. Mas a essência de nosso conhecimento sobre a batalha de Maratona tem sido há muito verificada por todo homem instruído, verificada por sua leitura não apenas de histórias que se referem diretamente a essa batalha, mas por toda a sua leitura, por todas as suas conversas, por todo o seu conhecimento sobre o mundo civilizado, não apenas do passado, mas também, e principalmente, da vida presente do mundo civilizado, a vida na qual ele próprio está tomando parte. Se a batalha de Maratona não tivesse sido travada e se os atenienses não a tivessem vencido, toda a história da Grécia seria diferente, o curso inteiro da história subsequente do mundo civilizado teria sido diferente e nossa vida presente seria diferente (TCHERNICHÉVSKI 1953c, p. 183; 184, tradução nossa). ${ }^{10}$

Ao trazer a discussão sobre o caráter científico da história como mais um exemplo para sua exegese sobre o caráter concreto, essencial e material do conhecimento, Tchernichévski termina por delinear uma certa concepção de história. Para ele, como visto acima, o que define o caráter científico da história, apesar de ela poder conter erros e imprecisões (assim como qualquer outra ciência), é a sua validação prática ao longo do tempo entre os "homens instruídos". Por um lado, os conhecimentos duvidosos e inverídicos da história não a invalidam por completo e, por outro, é principalmente a vida presente do mundo civilizado que a confirma.

Dessa maneira, é também o presente que legitima o conhecimento histórico. O atual estado das coisas, tal como é apreendido pelos estudos ou mesmo pelo senso comum, é o que confere o caráter de realidade à história. As percepções e necessidades do presente auxiliam na definição do passado:

Para um homem instruído, o resultado da batalha de Maratona é um dos mais óbvios fatores de nossa civilização. A esses importantes fatos associam-se outros cuja autenticidade repousa inabalavelmente na autenticidade dos primeiros. Mas o que encontramos em relação ao nosso conhecimento da história? Que ele indubitavelmente contém muita informação inautêntica e muitas opiniões erradas; mas ele contém conhecimento, cuja autenticidade é tão inabalável para um homem instruído que ele não pode sujeitá-la à dúvida sem renunciar à razão (TCHERNICHÉVSKI 1953c, p. 184, tradução nossa). ${ }^{11}$

Ora, cabe se perguntar: uma vez definidas como medidas da autenticidade do conhecimento histórico a sua validade e possibilidade de constatação no

\footnotetext{
${ }^{10}$ No original: "Take, for example, one of the sciences in which the admixture of the inauthentic is largest, viz., history. "The Athenians defeated the Persians at Marathon," is this authentic or doubtful? [...] The details of our information about, say, the battle of Marathon, can and should be verified, and many of them which seem to be quite authentic may prove to be doubtful or untrue. But the essence of our knowledge about the battle of Marathon has long ago been verified by every educated man, verified by his reading not only of stories relating directly to this battle, but by all his reading, by all his conversations, by all his knowledge about the civilized world, not only of the past, but also, and mainly, of the present life of the civilized world, the life in which he himself is taking part. If the battle of Marathon had not been fought, and if the Athenians had not been victorious in it, the whole history of Greece would have been different, the entire course of the subsequent history of the civilized world would have been different, and our present-day life would be different".

${ }^{11}$ No original: "For an educated man, the result of the battle of Marathon is one of the obvious factors of our civilization. With these important facts are associated others, the authenticity of which rests unshakeably upon the authenticity of the former. But what do we find in relation of our knowledge of history? That it undoubtedly contains very much unauthentic information, and very many wrong opinions; but it contains knowledge, the authenticity of which is so unshakeable for an educated man that he cannot subject it to doubt without renouncing reason".
} 
presente, qual seria a unidade de medida a se utilizar, ou seja, em qual critério confiar a avaliação de nosso conhecimento histórico? Na razão. Mas não em qualquer razão: unicamente naquela empírica, aferível à luz dos fatos concretos, como a que nos permite avaliar a mudança de temperatura da água, as operações da aritmética ou as batalhas militares que, acumuladas umas sobre as outras, originaram a atual civilização: "A razão testa tudo. Mas todo homem instruído possui considerável conhecimento já testado por sua razão de tal maneira que ele não o pode sujeitar à menor dúvida enquanto permanecer um homem de mente sã" (TCHERNICHÉVSKI 1953c, p. 184, tradução nossa). ${ }^{12}$

A razão, segundo Tchernichévski, não é, portanto, a mesma razão advogada pelo ilusionismo. A sua razão alcançaria a essência das coisas em si. A aterrissagem da razão, da ideia à matéria, pretendida por Tchernichévski, ao contrário do que pode deixar transparecer o seu ensaio ora em análise, não se dá em terreno puramente determinista ou mecânico. Se for tomado como referência para a elaboração de uma concepção de história de Tchernichévski um outro ensaio do autor, já analisado anteriormente, "O Princípio Antropológico na Filosofia", poder-se-á constatar sem dificuldades que o autor tateia uma filosofia mais bem elaborada e esboça os próprios rudimentos de uma certa dialética; para avaliar esse avanço, é necessário considerar o acesso limitado do autor à obra de Hegel e a sua ignorância dos trabalhos de Marx. Entrincheirado pela censura czarista, que cerceava não apenas a sua livre expressão, como também o acesso a obras proibidas e mesmo a citação expressa de autores perigosos à autocracia, Tchernichévski avançou consideravelmente dentro do seu permitido círculo de silêncio.

De maneira muito tímida, fez uma primeira tentativa de dar à sua razão um caráter dialético, mais dinâmico que aquele proporcionado pelo empirismo puro dos naturalistas. Isso fica evidente na sua crítica a Mill, em seu "O Princípio Antropológico na Filosofia". Diante dos debates sobre a extensão do sufrágio aos homens trabalhadores em 1860 na Inglaterra, Mill abandona a sua defesa teórica inicial do assunto e parte para uma posição política mais cautelosa, sugerindo que deveria ser feito um estudo para avaliar a eficácia da medida. Tchernichévski denuncia a sua vacilação, demonstrando que o desenvolvimento histórico da vida social não segue necessariamente uma linha racional:

Por que ele [Mill] agiu daquela maneira? Apenas devido ao seu fortíssimo desejo de que o desenvolvimento da vida social devesse seguir linhas absolutamente racionais. Isto não acontece [no entanto] em importantes situações seja na vida de um indivíduo, seja na vida de uma nação. Apenas coisas de pouca importância são feitas tão friamente, calmamente, deliberadamente e racionalmente. [...] Veja como o feudalismo foi abolido, ou como a Inquisição foi destruída, ou como a classe média conquistou seus direitos, ou, em geral, como todo grande mal foi abolido, ou como toda importante reforma foi introduzida. Mill compreende isto muito bem

\footnotetext{
12 No original: "Reason tests everything. But every educated man possesses considerable knowledge already tested by his reason, and it has proved to be such as he cannot subject to the slightest doubt while he remains a man of sound mind".
} 
como uma verdade científica, como um princípio geral do desenvolvimento histórico (TCHERNICHÉVSKI 1953b, p. 59; 61, tradução nossa). ${ }^{13}$

No entanto, a compreensão teórica de Mill não Ihe permitiu se desvencilhar de seus interesses políticos, completa Tchernichévski. Por ora, mais importante que o caráter ideológico da posição do economista inglês, é constatar a compreensão histórica do nosso autor. Tchernichévski prossegue apresentando diversos exemplos nos quais as emoções e as paixões humanas podem interferir no desenrolar do desenvolvimento histórico, demonstrando que a história não está toda ela vinculada a um esquema racional. Ele não utiliza expressamente o termo "dialética", mas é claro que se aproxima desse conceito e defende tal concepção. A distância que mantém de uma filosofia mais bem elaborada, como a hegeliana, ou do refinamento materialista do conceito, tal como se encontra em Marx, não deve impedir de constatar a dialética, em seus rudimentos, em seu trabalho.

A história, como ciência moral produtora de conhecimento concreto, essencial e irrefutável segundo as evidências do presente, opera e tem à sua disposição, conforme Tchernichévski, a razão que Ihe cabe, dialética.

\section{História e representação}

Em sua tese de admissão, "As relações estéticas da arte com a realidade" (1855), Tchernichévski também aborda alguns traços de sua concepção da história. A tese, como o próprio autor enfatiza no prefácio à terceira edição, de 1888, "é uma tentativa de aplicar as ideias de Feuerbach na solução dos problemas fundamentais da estética" (TCHERNICHÉVSKI 1953a, p. 416, tradução nossa). ${ }^{14}$ Salienta que "o autor não reclama para si [refere-se a si mesmo em terceira pessoa no prefácio] nada de novo" (TCHERNICHÉVSKI 1953a, p. 416, tradução nossa). ${ }^{15}$ Da mesma maneira como tratará, cinco anos mais tarde, em "O princípio antropológico na filosofia", de seu materialismo a partir das ideias de Feuerbach, em "As relações estéticas da arte com a realidade", trata da estética conforme as concepções do mesmo autor.

O seu ensaio se inicia com uma discussão sobre o belo e o sublime na obra de arte. O autor critica a arte tradicional, a arte pela arte, que, segundo ele, não teria interesse ou preocupação pela vida real. Para ele, "a realidade é superior ao ideal. Portanto, a vida real é superior à arte. Assim, conclui que o belo está não na arte, mas na vida real" (PAPERNO 1988, p. 160, tradução nossa). ${ }^{16} \mathrm{O}$ autor propõe expandir o conteúdo da arte para além da expressão da beleza e do sublime, abrangendo a totalidade da vida real humana. Para tal,

\footnotetext{
${ }^{13}$ No original: "Why did he do so? Simply because of his excessively strong desire that the development of social life should proceed on absolutely rational lines. This does not happen in important affairs either in the life of an individual or in the life of a nation. Only minor things are done quite coolly, calmly, deliberately and rationally. See how feudalism was abolished, or how the Inquisition was destroyed, or how the middle class won its right, or, in general, how any great evil was abolished, or how any important beneficial reform was introduced. Mill understands this very well as a scientific truth, as general principle of historical development".

${ }^{14}$ No original: "is an attempt to apply Feuerbach's ideas to the solution of the fundamental problems of aesthetics".

15 No original: "The author made no claim whatever to saying anything new of his own".

${ }^{16}$ No original: "Reality, Chernyshevsky proclaimed, is superior to the ideal. Therefore, real life is superior to art. From this, it follows that beauty is to be found not in art but in real life".
} 
formula a sua teoria da reprodução da obra de arte, salientando, no entanto, como aparece em sua revisão à sua tese, também publicada em 1855, que a reprodução da vida não é o fim último do qual a obra de arte deve tratar com fidedignidade absoluta, mas apenas o seu método de criação.

Mas as palavras: "a arte é a reprodução dos fenômenos da natureza e da vida" definem apenas o método pelo qual são criados os trabalhos de arte. Ainda resta a questão sobre quais fenômenos a arte reproduz. Após definir o princípio formal da arte, é necessário, a fim de tornar o conceito completo, definir também o princípio real, ou conteúdo, da arte. Normalmente é dito que apenas a beleza e seus conceitos afins - o sublime e o ridículo - servem como conteúdo da arte. O autor é da opinião que esta concepção é muito estreita e afirma que a esfera da arte abrange tudo na vida e na natureza que é de interesse do homem (TCHERNICHÉVSKI 1953a, p. 402, tradução nossa). ${ }^{17}$

Ainda na revisão que escreveu do seu próprio trabalho, Tchernichévski defende-se contra as tentativas de assimilação de sua Estética como uma simples e mecânica teoria da imitação: "o objetivo da reprodução é assistir a imaginação e não iludir os sentidos como a imitação pretende, e não é um mero passatempo, como a imitação, mas trabalha com um objetivo real" (TCHERNICHÉVSKI 1953a, p. 401 , tradução nossa).$^{18}$

Partindo de seus pressupostos filosóficos e da sua teoria da reprodução, Tchernichévski descreve, então, o que seria o objetivo do trabalho do artista:

A função essencial da arte é reproduzir os fenômenos que interessam ao homem em sua vida real. [...] O poeta ou o artista não abdica de sua condição humana e não pode evitar, mesmo que deseje, pronunciar o seu julgamento em relação ao objeto de trabalho [a realidade]. Esse juízo é expresso em seu trabalho - o que é uma outra função da arte, terminando por se situar também entre as atividades morais do homem. [...] Neste caso [quando se dedica a fenômenos da vida real] o artista se torna um pensador, e os trabalhos de arte, embora circunscritos à esfera própria da arte, adquirem relevância científica (TCHERNICHÉVSKI 1953a, p. $374 ; 375$, tradução nossa). ${ }^{19}$

O fato de o artista, sendo humano, em sua obra, emitir um juízo sobre o seu objeto, faz da arte uma atividade moral, "uma intermediária entre o homem e a realidade" (PAPERNO 1988, p. 164, tradução nossa). ${ }^{20}$ Mais, quando

\footnotetext{
17 No original: "But the words: 'art is the reproduction of the phenomena of nature and of life' define only the method by which works of art are created. There still remains the question as to what phenomena art reproduces. After defining the formal principle of art it is necessary, in order to make the conception complete, to define also the real principle, or content, of art. Usually it is said that only beauty and its subsumed concepts - the sublime and the ridiculous - serve as the content of art. The author is of the opinion that this conception is too narrow, and he asserts that the sphere of art embraces everything in life and nature that is of interest to man".

18 No original: "the object of reproduction is to assist the imagination and not to deceive the senses as imitation wants to do, and it is not a mere pastime, like imitation, but work with a real aim".

19 No original: "The essential purpose of art is to reproduce what is of interest to man in real life. [...] The poet, or artist, being unable to cease to be a man, cannot, even if he wanted to, refrain from pronouncing judgement on the phenomena he depicts. This judgment is expressed in his work - this is another purpose of art, which places it among the moral activities of man. [...] In such a case, the artist becomes a thinker, and works of art, while remaining in the sphere of art, acquire a scientific significance".

${ }^{20}$ No original: "an intermediary between man and reality".
} 
tem por objeto questões da vida real, o trabalho do artista não é apenas uma mera atividade, mas adquire relevância científica. Temos até aqui, portanto, que ciência (ciência moral), para o autor, define-se por seu método (semelhante ao das ciências exatas), pela utilização da razão (concreta, materialista) e, agora, pela emissão de juízo do cientista/artista sobre o objeto - sempre real - sobre o qual se debruça ou reproduz.

Tchernichévski eleva uma ponte entre a arte e a ciência (particularmente a ciência moral), possível apenas pela semelhança entre os seus objetos - a realidade - e o juízo que ambas articulam e emitem sobre eles.

Não é a ciência simplesmente uma abstração da vida, a sua representação em fórmulas? Tudo o que a ciência e a arte expressam é encontrado na vida real na sua mais plena e mais perfeita forma, com todos os seus vivos detalhes [...] Para os fenômenos da vida real tudo é verdade, nada é negligenciado, não sofrem daquela visão limitada e estreita comum a toda atividade humana. Como instrução ou aprendizagem, a vida é mais plena, verdadeira e inclusive mais artística que todos os trabalhos dos acadêmicos e poetas. No entanto, a vida, por si, não revela os seus fenômenos para nós; não lhe cabe postular axiomas. Isso é feito pelos trabalhos da ciência e da arte. [...] A ciência e a arte (poesia) são manuais para os iniciantes no estudo da vida (TCHERNICHÉVSKI 1953a, p. 375; 376 , tradução nossa). ${ }^{21}$

A vida real seria, a um só tempo, o critério de partida, o método de abordagem e o juízo final. Estaria por sobre toda e qualquer atividade humana em verdade, plenitude e beleza. Isso permite defender Tchernichévski contra as acusações de que a sua teoria da reprodução se reduziria a uma mera imitação da realidade. Para ele, nada é como a própria vida, nenhuma atividade é capaz de abrangê-la em sua totalidade, nem de superá-la.

Ao aproximar a arte e a ciência em relação ao papel necessariamente limitado desempenhado por ambas ao reproduzirem a vida, Tchernichévski encontra, enfim, espaço para tratar da história:

A relação da arte com a vida é a mesma relação desta com a história; a única diferença em seu conteúdo é que a história, ao abordar a vida da humanidade, trata principalmente das verdades factuais, enquanto a arte nos brinda com estórias sobre homens nas quais a fidelidade à verdade factual cede espaço à verdade psicológica e moral. A primeira função da História é reproduzir a vida; a segunda, que não é desenvolvida por todos os historiadores, é explicá-la. Ao não realizarem a segunda função, os historiadores permanecem meros cronistas e seus trabalhos se prestam meramente como material ao verdadeiro historiador, ou como material de leitura que satisfaz a curiosidade. Por outro lado, ao levarem a cabo a sua segunda função, os historiadores tornam-se pensadores e, como consequência, seus trabalhos adquirem mérito científico. Exatamente o

\footnotetext{
${ }^{21}$ No original: "Is not science simply the abstraction of life, the placing of life within a formula? Everything that is expressed by science and art is to be found in life, and to be found in its fullest and most perfect form, with all its living details [...] In the events of real life everything is true, nothing is overlooked, there is not that one-sided, narrow view from which all the works of man suffer. As instruction, as learning, life is fuller, truer and even more artistic than all the works of scholars and poets. But life does not think of explaining its phenomena to us, it is not concerned with deducing axioms. In the works of science and art this is done. [...] Science and art (poetry) are a Handbuch for those who are beginning to study life".
} 
mesmo pode ser dito da arte. A história não existe para competir com a vida real; a história reconhece que as suas pinturas são pálidas, incompletas, mais ou menos distorcidas, ou de todo limitadas [se comparadas à vida histórica real]. A estética deve reconhecer que a arte também, e pelas mesmas razões, não pode nem mesmo pensar em se comparar com a realidade [como imitação perfeita], muito menos acreditar que a supera em beleza (TCHERNICHÉVSKI 1953a, p. 376; 377, tradução nossa).22

A história, assim como a arte, tem como função reproduzir a vida. Tchernichévski percorre, ao analisar a história, o mesmo traçado exegético que descreveu ao analisar a arte: o artista emite juízo, o historiador emite juízo; a arte é uma atividade moral, a história é uma atividade moral; ao tratar da realidade, a arte adquire relevância científica, enquanto a história, como trata de fatos reais, é uma ciência moral. Ambas, no entanto, estão aquém da plenitude da vida.

A história, lembre-se, "uma das ciências na qual a dose de inautenticidade é maior", é posta, não por acaso, ao lado da arte. Na polêmica contra os defensores da arte pela arte, o autor saca contra todos o argumento de que a arte jamais substituirá a vida, que tal intento não passaria de um idealismo subjetivista e, dadas as condições sociais em que tradicionalmente era produzida a obra de arte, elitista. A arte não deveria se constranger em ser inferior, até mesmo em beleza, à própria vida, à própria realidade. Deveria olhar para a história e aprender com ela. A história é uma ciência resignada com as suas "pinturas pálidas", "incompletas", "distorcidas ou de todo limitadas" da realidade.

\section{Esboço de uma filosofía da história}

Os fragmentos de sua concepção de história, ou mesmo de uma possível filosofia da história, trazidos à luz ou remontados por Tchernichévski a partir, principalmente, dos trabalhos de Feuerbach e presentes nos três ensaios analisados, permitem esboçar um sistema razoavelmente coerente para a sua compreensão histórica.

Segundo Tchernichévski, uma vez que, para o seu desenvolvimento, a história poderia - e deveria - lançar mão dos mesmos procedimentos utilizados pelas ciências exatas, ela é, portanto, uma ciência, uma ciência moral. As suas limitações, ou o seu ainda elevado grau de inautenticidade (em meados do século XIX) se deviam apenas à sua pouca maturidade em relação às ciências exatas, que já haviam se desenvolvido e se cunhado como tais há um longo tempo.

\footnotetext{
22 No original: "The relation of art to life is the same as that of history; the only difference in content is that history, while speaking of the life of mankind, is concerned mainly with the factual truth, whereas art gives us stories about the lives of men in which the place of factual true is taken by faithfulness to psychological and moral truth. The first function of history is to reproduce life; the second, which is not performed by all historians, is to explain it. By failing to perform the second function, the historian remains a mere chronicler and his work serves merely as material for the genuine historian, or as reading matter to satisfy curiosity. When performing this second function, the historian becomes a thinker and, as a consequence, his work acquires scientific merit. Exactly the same must be said about art. History does not set out to compete with real historical life; it admits that the pictures it paints are pale, incomplete, more or less incorrect, or at all events, one-sided. Aesthetics must admit that art too, and for the same reasons, must not even think of comparing itself with reality, and still less of excelling it in beauty".
} 
Se, por um lado, o seu grau de inautenticidade não a alijaria do panteão científico, por outro, também não Ihe retiraria a capacidade ainda assim restante de revelar um conhecimento concreto, verdadeiro e não aparente do real. A essencialidade do seu conhecimento seria verificada pelo acúmulo de fatos ao longo do tempo que são tidos como necessários para se alcançar o presente. O seu critério de verdade histórica é, em última instância, o presente. Obviamente, não qualquer presente, mas aquele no qual estão plantadas as raízes do futuro, segundo as concepções filosóficas, éticas e políticas defendidas por Tchernichévski.

À história, sendo uma ciência moral em meio a tantas outras, caberia uma função particular: reproduzir a vida de acordo com as verdades factuais e, mais, explicá-la segundo o juízo do historiador (Marx já havia ido mais adiante, em suas teses sobre Feuerbach [MARX 2007], em relação ao filósofo: transformá-la). Dessa maneira, a história daria conta, a um só tempo, do passado, do presente e do futuro.

Não é demais salientar, pela última vez, que para Tchernichévski a história poderia oferecer apenas "pinturas pálidas" ou "limitadas" da realidade. No entanto, tal caráter da história é a própria expressão tanto das limitações humanas do historiador (dos limites de sua cognição) e da dinâmica própria da relatividade do conhecimento humano (que se desenvolve sem negar por completo o conhecimento anterior e sem negar a existência de um conhecimento verdadeiro concreto), quanto, por último, do limite posto a toda atividade humana (como referido sobre a arte), que é a insuperabilidade da vida real.

120 o escrutínio do conhecimento histórico seria feito pela razão e por sua relevância social. A razão de que se mune o historiador, no entanto, não é aquela fria, teórica e incapaz de se sensibilizar com o valor das transformações políticas históricas. Não é como a razão de Mill, que não lhe permitiu defender o avanço político da expansão do sufrágio na Inglaterra em 1860. À razão proposta por Tchernichévski é permitido sofrer os abalos passionais, radicais e transformadores da história. Tal concepção, ao se aproximar de uma visão dialética, afasta o nosso autor, ainda que não por completo, de uma filosofia puramente mecânica e determinista.

Tem-se, dessa maneira, uma primeira tentativa de sistematização de uma possível filosofia da história tchernichevskiana, de acordo com as suas concepções expostas nos ensaios "O princípio antropológico na filosofia", "O caráter do conhecimento humano" e "As relações estéticas da arte com a realidade". Em sua filosofia da história há desde uma concepção própria de ciência e de método, passando pela legitimação, entre as ciências, da ciência moral (onde se localiza a história) até, por final, a apresentação dos rudimentos de uma razão dialética que deveria guiar o historiador em seu ofício. Inegavelmente, a história - como as demais ciências e a arte -, para Tchernichévski, aparecia como tendo um papel social a cumprir. Estava necessariamente vinculada à sua filosofia materialista e ao interesse da vida e do homem, o que não seria outra coisa, naquele momento, senão se colocar a serviço da emancipação geral da sociedade russa em relação à tutela czarista. Há um apelo prático visível em sua teoria, além da crítica a toda outra filosofia que assim não se comportasse. 


\section{Discussão}

O desenvolvimento de toda a intelectualidade russa durante o século XIX se dá em franco intercâmbio com as ideias provenientes da Europa Ocidental. No entanto, a assimilação do ideário ocidental não se dava de maneira automática ou mecânica, de forma a impossibilitar a emergência das próprias questões russas e de seu pensamento original. A realidade russa pulsa nos trabalhos de Tchernichévski na mesma medida em que pulsam as filosofias hegeliana e pós-hegeliana (com destaque para Feuerbach), o socialismo das diversas correntes francesas e a economia dos liberais clássicos, em especial Adam Smith e John Stuart Mill.

Os acontecimentos e transformações históricas por que passava e em função dos quais era abalada a sociedade russa no século XIX envolveram e foram influenciados por sua intelectualidade. O lugar político que ocuparam muitos dos membros da intelligentsia fez com que os mais proeminentes deles ousassem elaborar soluções políticas para os dilemas de sua época e que os compreendessem teoricamente com a ajuda do pensamento progressista do Ocidente. Tchernichévski tentou erguer em sua obra uma síntese filosófica e política na qual estivessem presentes as contribuições do Ocidente e as mais que imprescindíveis contribuições da própria Rússia e dos seus pensadores.

As influências presentes em seus trabalhos de nomes como Hegel, Feuerbach, Fourier e Mill não devem valer à sua obra a característica de não original. Qual pensador do século XIX poderia prescindir de tais contribuições para as suas respectivas áreas? Resta saber se a interpretação dada por Tchernichévski aos trabalhos dos autores nos quais se apoia são válidas e se lhes acrescenta algo. Para a primeira pergunta, quanto à validade de sua interpretação, este artigo demonstrou que há nos ensaios analisados um grande esforço do autor de tratar questões filosóficas e estéticas de acordo com o pensamento feuerbachiano. Questionar-se o pensamento de Feuerbach excede nosso escopo no presente artigo. Em relação à segunda interrogação, sobre a originalidade de suas contribuições, este artigo apresentou as limitações que impediram ao autor a construção de um sistema filosófico mais bem elaborado e refinado, a saber, por um lado, a censura czarista a obras cruciais e mesmo a referências textuais de fontes perigosas ao regime, além da precocidade da prisão de Tchernichévski (o autor permaneceu preso dois terços de sua vida produtiva), e, por outro lado, o engajamento político particular de Tchernichévski, em função do qual concebia a simplificação e divulgação das ideias revolucionárias como uma tarefa tão relevante quanto a elaboração de um novo pensamento. Não é demais salientar que foi negado a Tchernichévski o direito de gozar plenamente de sua maturidade intelectual, o que impossibilita qualquer especulação sobre a sua real capacidade nesse sentido.

Está claro que Tchernichévski não se dedicou deliberadamente à elaboração de uma obra específica sobre a filosofia da história. As considerações que tece a respeito da história estão sempre esparsas ao longo do caminho de outros percursos que desenvolve. No entanto, isso não impede de reuni-las na sistematização aqui proposta. Como já foi salientado anteriormente, a filosofia 
tchernichevskiana também não se destaca por seu refinamento ou por sua complexidade. O autor apenas esboça alguns sinais da concepção dialética, pouco valendo-se dela para conferir às suas concepções filosóficas uma visão mais bem elaborada. No entanto, é importante, sob pena de se resvalar em um posicionamento reducionista e anacrônico, levar em consideração e ponderar em que condições e com que objetivos foi realizada a obra de nosso autor, como feito anteriormente.

Por fim, a apresentação, sistematização e análise da obra filosófica de Tchernichévski revelam que o autor ocupa um lugar destacado na história do pensamento russo e que as suas contribuições no campo do pensamento histórico devem ser consideradas se se pretender, com maior riqueza, compreender como se desenvolveu a filosofia da história russa no século XIX e a singular assimilação e atualização das concepções científicas e filosóficas advindas da Europa Ocidental por parte de sua intelligentsia.

\section{Referências bibliográficas}

BERLIN, Isaiah. Pensadores russos. São Paulo: Companhia das Letras, 1988. ENGELS, Friedrich; MARX, Karl. A ideologia alemã. São Paulo: Boitempo, 2007. GARCIA-VALVERDE, Orlando; INGERFLOM, Claudio Sergio Nun. Lenin Rediscovered, or Lenin Redisguised? Kritika: Explorations in Russian and Eurasian History, v. 10, n. 1, p. 139-168, 2009.

122 GRIGORIAN, Mamikon Meerovitch. N. G. Chernyshevsky's world outlook. In: CHERNYSHEVSKY, Nikolai. Selected Philosophical Essays. Moscou: Foreign Languages Publishing House, 1953, p. 5-46.

PAPERNO, Irina. Chernyshevsky and the Age of Realism: A Study in the Semiotics of Behavior. Stanford: Stanford University Press, 1988.

POHORAL, Georgine Barbara. The philosophical ideas of N. G. Chernyshevsky. Dissertação (Mestrado em Artes). The Faculty of Graduate Studies Department of Slavonic Studies, Univesity of British Columbia, 1980.

RANDALL, Francis B. N.G. Chernyshevskii. Nova York: Twayne Publishers Inc, 1967.

SCANLAN, James P. Nikolaj Chernyshevsky and the Philosophy of Realism in Nineteenth-Century Russian Aesthetics. Studies in Soviet Thought, v. 30, n. 1, p. 1-14, Springer, 1985.

TCHERNICHÉVSKI, Nikolai. The Aesthetical Relation of Art and Reality. In:

Selected Philosophical Essays. Moscou: Foreign Languages Publishing House, 1953a, p. 281-381.

. The Anthropological Principle in Philosophy. In: Selected

Philosophical Essays. Moscou: Foreign Languages Publishing House, 1953b, p. 49-135.

. The Character of Human Knowledge. In: 
Philosophical Essays. Moscou: Foreign Languages Publishing House, 1953c, p. 166-184.

WALICKI, Andrzej. A History of Russian Thought from the Enlightenment to Marxism. Stanford: Stanford University Press, 1979.

WOERHLIN, William F. Chernyshevskii: the man and the journalist. Cambridge: Harvard University Press, 1971. 